\title{
Ubiquitin Carboxyl-Terminal Hydrolase 17
}

National Cancer Institute

\section{Source}

National Cancer Institute. Ubiquitin Carboxyl-Terminal Hydrolase 17. NCI Thesaurus. Code C120056.

Ubiquitin carboxyl-terminal hydrolase 17 (530 aa, $60 \mathrm{kDa}$ ) is encoded by the human USP17L2 gene. This protein plays a role in the mediation of protein deubiquitination. 